ГCASE REPORT

Volume 16 Supp 12021

DOI: 10.21315/aos2021.16.51.9

ARTICLE INFO

Submitted: 02/03/2021

Accepted: 27/05/2021

Online: 22/09/2021

\section{Skeletal Class II Malocclusion Treatment with Combined Twin Block and Lip Bumper Appliances: A Case Report}

\author{
Hilda Fitria Lubis, Nurhayati Harahap, Ananda Permata Sari ${ }^{*}$ \\ Department of Orthodontics, Faculty of Dentistry, Universitas Sumatera \\ Utara, Medan 20155, Sumatera Utara, Indonesia
}

${ }^{*}$ Corresponding author: anandaandri.dentist@gmail.com

To cite this article: Lubis HF, Harahap N, Sari AP (2021). Skeletal Class II malocclusion treatment with combined twin block and lip bumper appliances: A case report. Arch Orofac Sci, 16(Supp.1): 51-57. https://doi.org/10.21315/aos2021.16.s1.9

To link to this article: https://doi.org/10.21315/aos2021.16.s1.9

\begin{abstract}
Functional appliances have been used over a century in clinical orthodontic treatments for skeletal Class II malocclusion patients. Its popularity is attributed to its high patient adaptability and ability to produce rapid treatment changes. The twin block and lip bumper can be combined depending on the patient's cases. The purpose of therapy with twin block is effective in mandibular growth deficiencies to induce supplementary lengthening of mandibular by stimulating increased growth at the condylar cartilage. The patient was a ten-year-old male patient with skeletal Class II malocclusion. He had a convex facial profile, SNA (sella, nasion, A point) angle of $77.5^{\circ}$, SNB (sella, nasion, B point) angle of $73.0^{\circ}$, ANB (A point, nasion, B point) angle of $4.5^{\circ}$, overjet of $6.5 \mathrm{~mm}$, overbite of $11 / 41=5.0 \mathrm{~mm}$, $21 / 31=4.5 \mathrm{~mm}$, abnormal upper labial frenulum, crossbite in the second left premolar of maxilla, crowded anterior teeth of mandibular, deficiency of mandibular growth, lower lip sucking habit, anterior teeth of maxilla with diastema and proclination. Orthodontic treatment for patient is a combination of twin block and lip bumper appliances. After seven months, frenectomy is used to eliminate and correct the spacing in the frenulum. After 10 months, the patient's skeletal and profile had improved to skeletal Class I malocclusion, SNA angle of $78.0^{\circ}$, SNB angle of $75.0^{\circ}$, ANB angle of $3.0^{\circ}$, overbite and overjet of $4.0 \mathrm{~mm}$, and the lower lip sucking habit had stopped. Twin block and lip bumper appliances are particularly good alternative treatment in managing selected cases of skeletal Class II malocclusion.
\end{abstract}

Keywords: Functional appliance; lip bumper; skeletal Class II malocclusion; twin block

\section{INTRODUCTION}

Functional appliances have been used over a century in clinical orthodontic treatments for skeletal Class II malocclusion patients (O'Brien et al., 2003). The twin block appliance was originally developed for the treatment of skeletal Class II malocclusions (Clark, 2002). Its popularity is attributed to its high patient adaptability and ability to produce rapid treatment changes (Sharma \& Lee, 2005). The appliance consists of maxillary and mandibular acrylic plates with bite blocks, which interlock at a $70^{\circ}$ angle on closure while posturing the mandible forward (Baccetti et al., 2000; Jacobson, 2004; Bonde et al., 2015; Akhoon \& Mushtaq, 2018; Tariq et al., 2018). The twin block and lip bumper can be combined depending on the patients' cases. 


\section{CASE REPORT}

The patient is a ten-year-old Indonesian boy at the Dental and Mouth Hospital, Universitas Sumatera Utara, Medan. He was unhappy with the position of his forwardly upper front teeth. On extraoral examination, the patient had a convex facial profile with a retrognathic mandibular and lips competent. There was no transverse asymmetry when viewed frontally (Fig. 1). On intraoral examination, the patient was in mixed dentition, the oral hygiene was moderate, and his molar relationship was Angle's Class II. He had $6.5 \mathrm{~mm}$ overjet, and his overbite was $11 / 41=5.0 \mathrm{~mm}$, $21 / 31=4.5 \mathrm{~mm}$, crossbite in the second left premolar of maxilla, crowded anterior teeth of mandibular, deficiency of mandibular growth, anterior teeth of maxilla with diastema and proclination (Fig. 2).
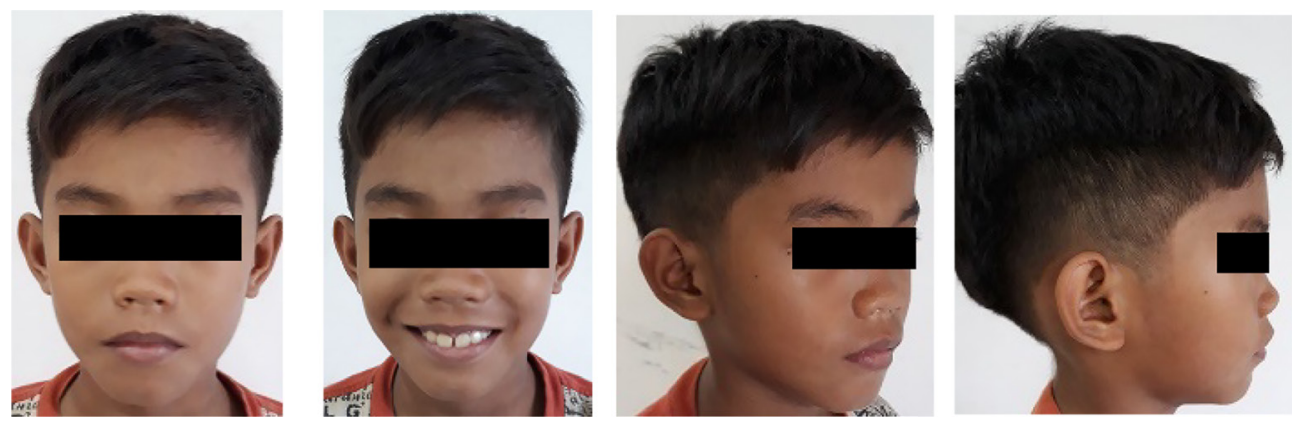

Fig. 1 Pre-treatment extraoral photographs.
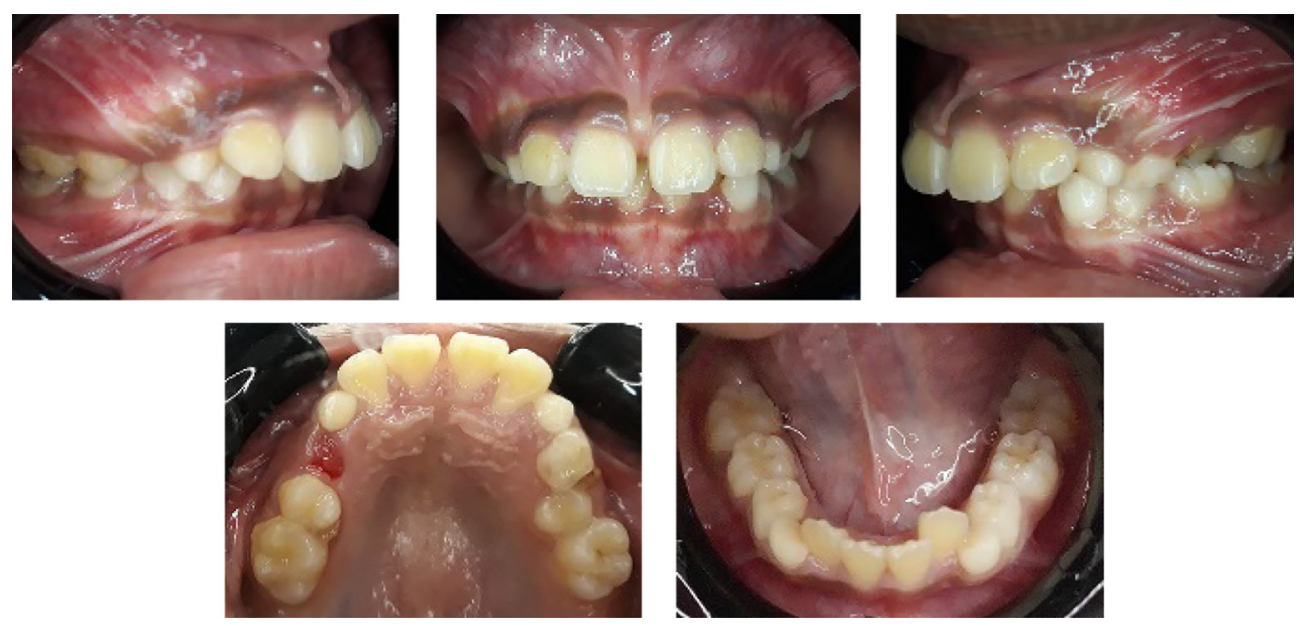

Fig. 2 Pre-treatment intraoral photographs. 


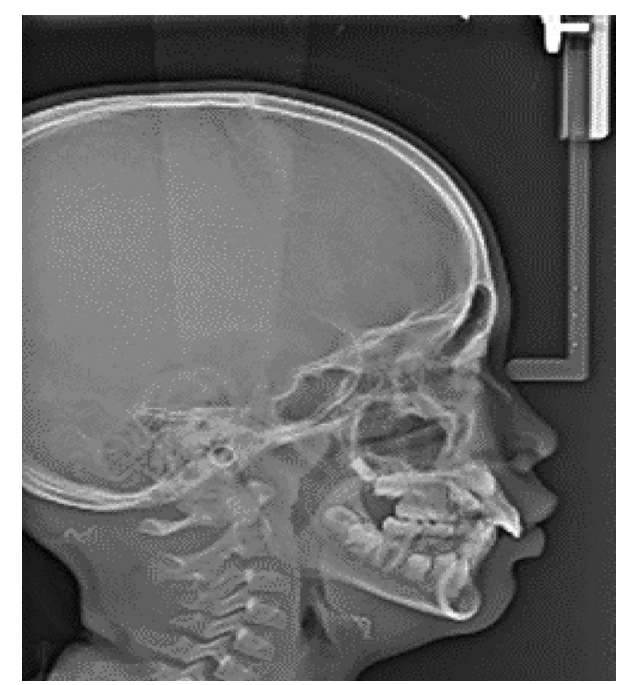

Fig. 3 Pre-treatment lateral cephalometric radiograph.

\section{CASE MANAGEMENT}

The patient was treated with combined twin block and lip bumper appliances. Screw was incorporated in the upper twin block to develop the arch form during the mixed dentition.

\section{Treatment Objectives}

1. Correction of skeletal Class II malocclusion.

2. Improving the relation of molar Class II Angle to Class I Angle.

3. Correction of overjet and overbite.

4. Correction of diastema and elimination of upper labial frenulum in central incisors.

5. Correction of convex facial profile.

6. Correction of crowded anterior mandibular.

7. Elimination of a lower lip sucking habit.

\section{Treatment Plan}

The patient had skeletal and dental Class II relationship and CVMI-1. The treatment was consisted of two phases. The first phase of the treatment was growth modification using twin block appliance. Prior to the utilisation of twin block appliance, extraction of radix

Table 1 Pre- and post-functional appliance cephalometric measurements (Steiner analysis)

\begin{tabular}{lcccc} 
Skeletal & Mean & SD & Before & After \\
\hline SNA $^{\circ}$ & $82.0^{\circ}$ & \pm 2.0 & $77.5^{\circ}$ & $78.0^{\circ}$ \\
SNB $^{\circ}$ & $80.0^{\circ}$ & \pm 2.0 & $73.0^{\circ}$ & $75.0^{\circ}$ \\
ANB $^{\circ}$ & $2.0^{\circ}$ & \pm 2.0 & $4.5^{\circ}$ & $3.0^{\circ}$ \\
NAPog $^{\circ}$ & $0.0^{\circ}$ & $\left(-8.5^{\circ}\right)$ to $10.0^{\circ}$ & $9.0^{\circ}$ & $6.0^{\circ}$ \\
MP : SN & $32.0^{\circ}$ & \pm 5.0 & $36.0^{\circ}$ & $36.0^{\circ}$ \\
NSGn ${ }^{\circ}$ Y axis) & $65.0^{\circ}$ & \pm 3.0 & $69.5^{\circ}$ & $71.0^{\circ}$ \\
Pog : NB mm & $2.0 \mathrm{~mm}$ & \pm 1.0 & $4.0 \mathrm{~mm}$ & $1.5 \mathrm{~mm}$ \\
SGo : NMe \% & $68.0^{\circ}$ & \pm 4.0 & $60.9 \%$ & $63.0^{\circ}$ \\
Wits appraisal & 0.0 & \pm 2.0 & $3.5 \mathrm{~mm}$ & $1.0 \mathrm{~mm}$ \\
\hline Dental & Mean & SD & Before & After \\
$1: \overline{1}^{\circ}$ & $130.0^{\circ}$ & $130.0^{\circ}$ to $150.5^{\circ}$ & $124.5^{\circ}$ & $122.0^{\circ}$ \\
$1:$ SN & $102.0^{\circ}$ & \pm 2.0 & $101.0^{\circ}$ & $104.0^{\circ}$ \\
$1:$ MP & $90.0^{\circ}$ & \pm 3.0 & $98.0^{\circ}$ & $98.5^{\circ}$ \\
$1:$ Apog mm & $2.7 \mathrm{~mm}$ & $(-1)$ to $5 \mathrm{~mm}$ & $9.0 \mathrm{~mm}$ & $9.5 \mathrm{~mm}$ \\
$1:$ NB mm & $4.0 \mathrm{~mm}$ & \pm 3.0 & $6.0 \mathrm{~mm}$ & $7.0 \mathrm{~mm}$ \\
E line : LS mm & $+1.0 \mathrm{~mm}$ & \pm 2.0 & $+5.5 \mathrm{~mm}$ & $+5.0 \mathrm{~mm}$ \\
E line : LI mm & $0.0 \mathrm{~mm}$ & \pm 2.0 & $+4.5 \mathrm{~mm}$ & $+5.0 \mathrm{~mm}$ \\
\hline & & & &
\end{tabular}


55 , teeth 53 and teeth 64 is needed due to its mobility. In addition, extraction of teeth 73 and 83 is also needed to eliminate crowded anterior teeth of mandibular. Twin block appliance had the following components (Fig. 4):

1. Interlock of occlusal bite blocks meeting at a $70^{\circ}$ angle.

2. Adam's clasps on upper and lower molars.

3. Screw to expand the upper arch.

4. Labial bow to retract the upper incisors.

5. Upper and lower base plates.

6. Finger spring at teeth 11 and 21 to space closure.

7. Finger spring at teeth 31,41 and 42 to correct midline.

8. $\mathrm{Z}$ spring in teeth 32 to push the tooth forward.

The patient was advised to wear the appliance for $12 \mathrm{~h}$ to $14 \mathrm{~h}$ per day as well as during eating if possible. The second phase of treatment used fixed orthodontic mechanotherapy for final detailing of occlusion.

\section{Treatment Progress}

After seven months of treatment, diastema centralis was still not corrected. Responding to that, frenectomy was done to eliminate diastema. After the application of twin block with combined lip bumper treatment for ten months, the following was achieved (Figs. 4 to 8 , Table 1 ):

1. Skeletal Class II malocclusion became skeletal Class I malocclusion.

2. SNA angle changed from $77.5^{\circ}$ to $78.0^{\circ}$, SNB angle changed from $73.0^{\circ}$ to $75.0^{\circ}$.

3. ANB angle changed from $4.5^{\circ}$ to $3.0^{\circ}$.

4. Overjet reduction changed from $6.5 \mathrm{~mm}$ to $4.0 \mathrm{~mm}$.

5. Overbite reduction $11 / 41$ changed from $5.0 \mathrm{~mm}$ to $4.0 \mathrm{~mm}, 21 / 31$ changed from $4.5 \mathrm{~mm}$ to $4.0 \mathrm{~mm}$.

6. Transverse measurement of maxillary interfirst molar width changed from $45 \mathrm{~mm}$ to $47 \mathrm{~mm}$.

7. Improvement of patient's facial profile.

8. Elimination of central diastema of maxilla as well as lower lip sucking habit.

9. A decrease of crowded anterior mandibular.
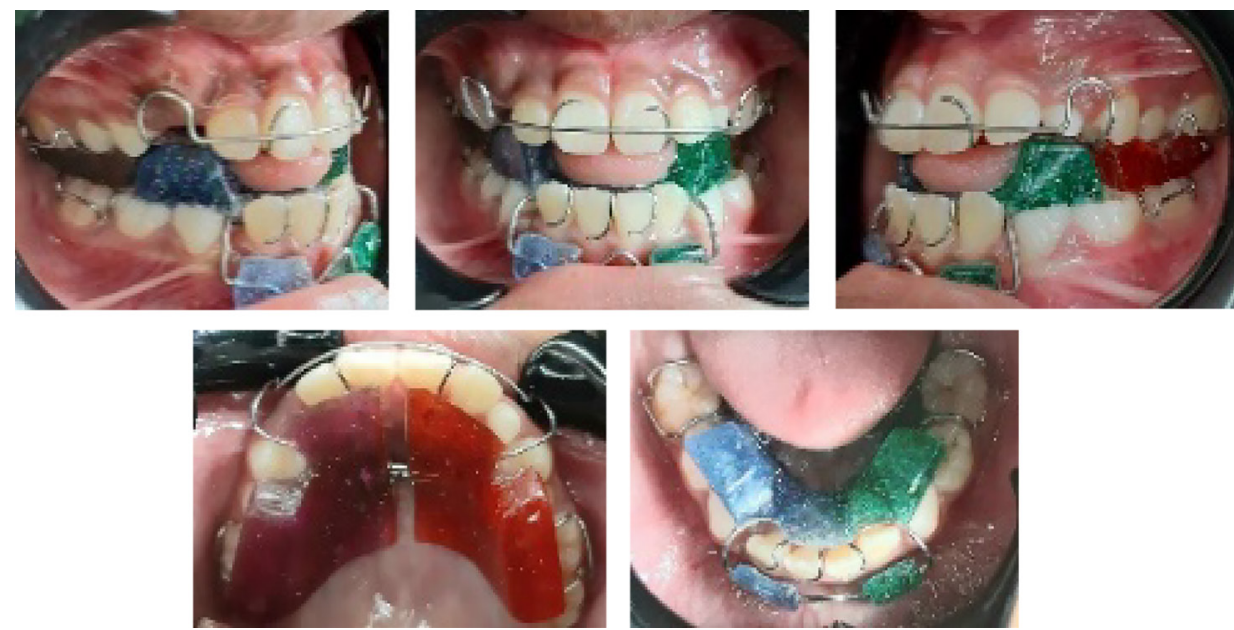

Fig. 4 The twin block appliance used in the present case. 

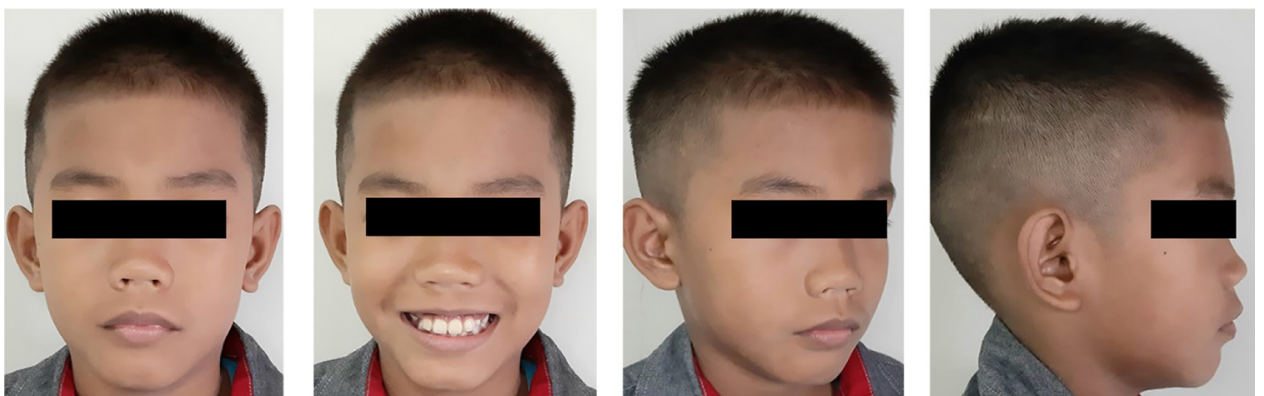

Fig. 5 Post-treatment extra oral photographs.
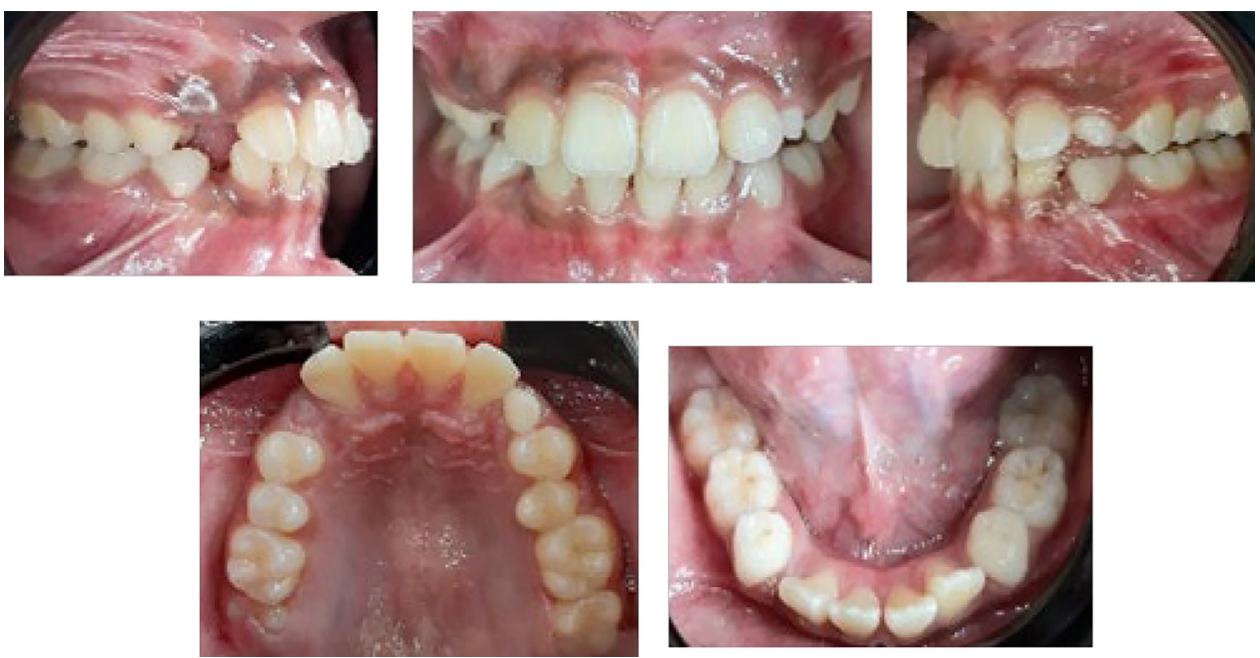

Fig. 6 Post-treatment intra oral photographs.
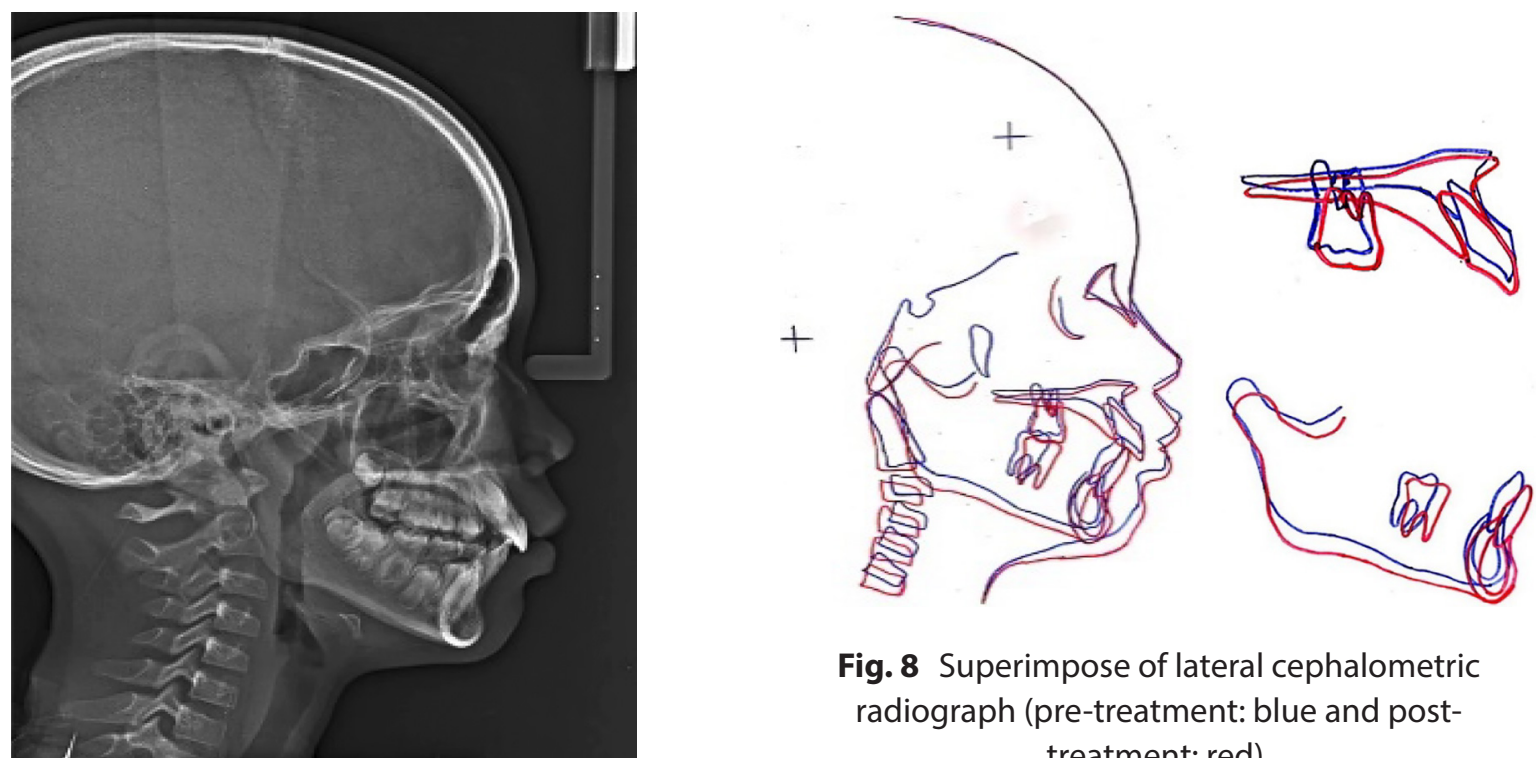

Fig. 8 Superimpose of lateral cephalometric radiograph (pre-treatment: blue and posttreatment: red).

Fig. 7 Post-treatment lateral cephalometric radiograph. 


\section{DISCUSSION}

Class II malocclusion might have any number of a combination of skeletal and dental components. Hence, identifying and understanding aetiology and expression of Class II malocclusion, as well as identifying differential diagnosis are helpful for its correction and to determine the treatment planning, whether it would be functional, orthodontic, or surgical (Vaghela et al., 2019). The selection of functional appliances is dependent upon several reasons which can be categorised into patient factors, for example, age, compliance and clinical, preference/familiarity, and laboratory facilities (Aminian et al., 2017; Rahhal, 2018). Twin block is very effective in mixed dentition phase and the usage of this appliance during growing phase with good patient cooperation produces the skeletal effect and some dentoalveolar effect (Akhoon \& Mushtaq, 2018; Tariq et al., 2018).

Functional appliances are designed to enhance forward mandibular growth in the treatment of distal occlusion by encouraging a functional displacement of the mandibular condyles downwards and forwards in the glenoid fossae. Adaptive remodelling may occur on both articular surfaces of the temporomandibular joint to improve the position of the mandible to correspond relatively to the maxilla (Clark, 2002). The lip bumper is a simple functional appliance and is usually well tolerated by patients. In orthodontics, lip bumpers have been used to gain arch length for the alignment of mild to moderately crowded dental arches, to correct molar rotations, to control anchorage loss, to improve labialis muscle activity, and to eliminate lower lip biting habit (Germeç \& Taner, 2005). Lip bumpers gain intra-arch space by removing the pressure of the buccal musculature, permitting lateral and anterior dentoalveolar development (Bishara, 2001).

The presence of a diastema less than approximately $2 \mathrm{~mm}$ may be considered normal at this stage of dental development, with the diastema often closing spontaneously upon eruption of the maxillary canines (Naini \& Gill, 2018). Neither the presence of an upper labial frenulum nor a maxillary dental midline diastema is enough of an indication for a frenectomy. Thus, further visualisation is needed to determine the diagnosis. The visualisation must show the blanching in the palatal mucosa when the upper lip is pulled away from the dentoalveolar as well as fibrous tissue from the labial frenulum passes between the central incisors, usually through an alveolar notch in the region of the diastema, and inserting into the palatal mucosa for it to become an indication (Naini \& Gill, 2018).

Frenectomy is almost contraindicated before orthodontic treatment. When frenectomy is indicated, the timing should be agreed between the orthodontist and surgeon. Frenectomy may be undertaken when the incisor teeth are orthodontically aligned, and space closure is imminent or partial space closure has been undertaken, for example, during orthodontic treatment (Naini \& Gill, 2018).

\section{CONCLUSION}

Twin block and lip bumper appliances are particularly good alternative treatment in managing selected cases of skeletal Class II malocclusion. Twin block is also effective for mixed dentition phase, and the lip bumper appliance also helped in eliminating the lower lip sucking habit and improve the labialis and mentalis muscle activity. After treatment, the lower lip position was improved.

\section{REFERENCES}

Akhoon AB, Mushtaq M (2018). Class II correction using twin block appliance: A case report. Int $\mathcal{F} A d v$ Res Idea Innov Tech, 4(1): 533-538. 
Aminian A, Sarvareh Azimzadeh S, Rahmanian E (2017). Cl II malocclusion treatment, using the modified twin block appliance coordinated with fixed orthodontics in a postmenarche patient. Case Rep Dent, 2017: 2525374. https://doi.org/10 $.1155 / 2017 / 2525374$

Baccetti T, Franchi L, Toth LR, McNamara JA Jr (2000). Treatment timing for twin-block therapy. Am $\mathcal{f}$ Orthod Dentofacial Orthop, 118(2): 159-170. https://doi.org/10.1067/ $\bmod .2000 .105571$

Bishara SE (2001). Textbook of Orthodontics, 1st edn. Philadelphia: W.B. Saunders Company.

Bonde PV, Kerudi VV, Patil N, Dolas SG, Patil HA (2015). Treatment of skeletal Class II malocclusion with twin-block. $\mathcal{F}$ Appl Dent Med Sci, 1(3): 57-61.

Clark WJ (2002). Twin Block Functional Therapy: Applications in Dentofacial Orthopaedics, 2nd edn. St. Louis: Mosby, pp. 3-5.

Germeç D, Taner TU (2005). Lower lip sucking habit treated with a lip bumper appliance. Angle Orthod, 75(6): 10711076. https://doi.org/10.1043/0003-3219 (2005)75[1071:LLSHTW]2.0.CO;2

Jacobson A (2004). Book review: Twinblock functional therapy: Applications in dentofacial orthopaedics, 2nd edn. Am $\mathcal{F}$ Orthod Dentofacial Orthop, 126(2): 262-263. https://doi.org/10.1016/j.ajodo .2004 .03 .003

Naini FB, Gill DS (2018). Oral surgery: Labial frenectomy: Indications and practical implications. Br Dent F, 225(3): 199-200. https://doi.org/10.1038/sj.bdj.2018.656
O'Brien K, Wright J, Conboy F, Sanjie Y, Mandall N, Chadwick S et al. (2003). Effectiveness of treatment for Class II malocclusion with the Herbst or twin-block appliances: A randomized, controlled trial. Am $\mathcal{F}$ Orthod Dentofacial Orthop, 124(2): 128-137. https://doi.org/10.1016/s08895406(03)00345-7

Rahhal AA (2018). Treatment of skeletal CL II patient with maximum lower incisor protrusion and minimum overjet with rahhal functional appliance. Open $\mathcal{f}$ Stomatol, 8(12): 319-325. https://doi.org/ 10.4236/ojst.2018.812030

Sharma AA, Lee RT (2005). Prospective clinical trial comparing the effects of conventional twin-block and mini-block appliances: Part 2. Soft tissue changes. Am $\mathcal{F}$ Orthod Dentofacial Orthop, 127(4): 473-482. https://doi.org/10.1016/j.ajodo.2004.03.027

Singh G (ed.) (2015). Textbook of Orthodontics, 3rd edn. New Delhi: Jaypee Brothers Medical Publishers, pp. 133-135.

Tariq M, Maheshwari S, Asif S, Qamar Y, Pathak $S$ (2018). Effect of twin block appliance on a growing patient: A case report. Interven Pediatr Dent, 1(4): 61-64. https://doi.org/ 10.32474/IPDOAJ.2018.01.000117

Vaghela AM, Kubavat AK, Desai M, Modi HS, Modh A, Gor J (2019). Correction of skeletal Class II pattern using twin block appliance therapy: A case report. $\mathcal{F} \mathrm{Med}$ Sci Clin Res, 7(4): 726-729. https://doi.org/ $10.18535 / \mathrm{jmscr} / \mathrm{v} 7 \mathrm{i} 4.122$ 